p-ISSN 1693-9484, $e$-ISSN : 2621-8313

Majalah Ilmiah Bahari Jogja (MIBJ)

Vol. 17 No. 2, Juli $2019 \quad$ (84-90)

DOI : 10.33489/mibj.v17i2.212

(C) 2019 Akademi Maritim Yogyakarta

\title{
Perguruan Tinggi Kemaritiman Menghadapi Revolusi Industri 4.0
}

\author{
Wegig Pratama $^{1^{*}}$, Sri Sartini ${ }^{1}$ \\ ${ }^{1}$ Akademi Maritim Yogyakarta, Jl.Magelang KM 4,4, Yogyakarta 55284, Indonesia \\ *Corresponding Author. Email:wegigpratama@gmail.com. Telp:+628179449111
}

\begin{abstract}
Abstrak
Karya tulisan ini bertujuan untuk melakukan pengkajian terkait perkembangan era revolusi industri 4.0 yang masif dan tantangannya untuk setiap Perguruan Tinggi Kemaritiman dengan melakukan Literature review terhadap beberapa jurnal terkait. Hasilnya bahwa setiap Perguruan Tinggi Kemaritiman di Indonesia harus mempunyai kesiapan dan strategi dalam menghadapinya dengan segala kondisi yang ada. Konversi kurikulum berbasis digital, peningkatan sarana prasarana pembelajaran berbasis teknologi serta peningkatan Sumber Daya Manusia (SDM) berkualitas menjadi kunci utama dalam menghadapi era ini.
\end{abstract}

\section{Kata Kunci: Perguruan Tinggi Kemaritiman, Revolusi Industri 4.0}

This paper is aimed to investigate the massive development of Industrial Revolution 4.0 and its challenges in particular for Indonesian Maritime Higher Education by conducting literature review towards some related journals. The result shows that each of Maritime Higher Education in Indonesia should have good readiness and strategies to cope with this era in any reason and condition. Digital-Based Curriculum conversion, upgrading in the learning infrastructure and tools, as well as qualifying human resources are the key points.

\section{Keywords: Maritime Higher Education, Industrial Revolution 4.0}

\section{PENDAHULUAN}

Memasuki pertengahan abad ke 21 merupakan era dimulainya revolusi industri 4.0 atau lebih dikenal dengan disruption era menjadi sebuah tantangan bagi dunia pendidikan tinggi di Indonesia tidak terkecuali Perguruan Tinggi Kemaritiman. Perkembangan yang sangat masif ini memberikan sebuah penekanan pada Perguruan Tinggi Kemaritiman untuk menyiapkan Sumber Daya Manusia (SDM) yang berkualitas sesuai dengan kebutuhan persaingan pada pada era revolusi industri 4.0 tersebut. Mengingat revolusi industri 4.0 menuntut implementasi pekerjaan yang berbasis pada teknologi komputerisasi/ teknologi cerdas dengan melibatkan penggunaan big data, sehingga peran SDM hanya sebagai pengontrol teknologi super canggih yang telah diciptakan.

Kobylinski (2016) yang mengemukakan bahwa ke depan di dunia pelayaran dimungkinkan tidak akan banyak membutuhkan crew di atas kapal, karena dimungkinkan telah tercipta kapal cerdas tanpa awak kapal yang beroperasi dengan mengandalkan sistem teknologi tinggi, yang merupakan isu refleksi masuknya revolusi industri 4.0. Selanjutnya Stanic et.al (2018) dalam artikelnya menegaskan 
bahwa pada era revolusi industri 4.0 ini perkembangan industri perkapalan tidak sekedar didasarkan pada peningkatan teknologi permesinan dan software yang canggih, tetapi lebih menekankan tiga hal meliputi: (1) sistem komputerisasi otomatis yang canggih, (2) keselamatan operasional kapal, dan (3) efisiensi biaya dan energi yang tidak banyak membutuhkan tenaga manusia. Lebih lanjut Hribernik (2016) menekankan bahwa ke depan akan lebih banyak kapal seperti robot yang lebih fleksibel digerakkan dengan pengawasan atau kontrol digital. Dari tiga pendapat diatas mengindikasikan bahwa ke depan industri maritim membutuhkan SDM relatif sedikit, karena peran teknologi robotic lebih menguat, hal ini diperlukan kesiapan SDM dalam menjawab tantangan tersebut.

Dampak revolusi industri 4.0 akan berpengaruh terhadap tata kelola di Perguruan Tinggi Kemaritiman dalam menyiapkan lulusannya agar bisa bersaing di dunia kerja, sebagai pusat perubahan dan inovasi harus mampu menyiapkan lulusan yang berkompeten, inovatif dan adaptif terhadap teknologi digital. Artinya Perguruan Tinggi harus membekali kepada peserta didiknya dengan literasi data yang berupa kemampuan dalam membaca analisis dan menggunakan informasi dari bank data. Dengan demikian, bagaimana kesiapan dan strategi perguruan tinggi kemaritiman di Indonesia dalam menghadapi tantangan era revolusi industri 4.0 sebagai upaya penyiapan lulusan yang berkompeten dan berkualitas menjadi hal penting yang harus diperhitungkan. Hal inilah yang menjadi kajian dalam penelitian library research pada karya ilmiah ini.

\section{KAJIAN LITERATUR}

Tulisan ini merupakan kajian pustaka library research yang bertujuan melakukan pengkajian mengenai konsep dan teori terkait topik yang diambil yakni terkait kesiapan dan strategi perguruan Tinggi Kemaritiman dalam menghadapi tantangan era Revolusi Industri 4.0 berdasarkan literatur yang ada. Kajian Pustaka ini menjadi dasar konsep dalam penemuan solusi pada masalah yang diambil.

\section{Transisi Menuju Industri Kemaritiman Cerdas}

Perkembangan inovasi industri kemaritiman saat ini telah memasuki era revolusi industri 4.0 yang memiliki percepatan sangat tinggi dibandingkan tiga revolusi industri sebelumnya. Seperti diketahui terdapat empat tahapan revolusi industri sebagai transisi perubahan inovasi, sebagaimana dikemukakan Lervold (2017) revolusi industri pertama dimulai tahun 1800-an yang ditandai ditemukannya mesin uap dan penggunaan mesin berbasis manufaktur, revolusi industri kedua pada tahun 1900-an ditunjukkan makin meluasnya penggunaan mesin-mesin dalam manufaktur, dan meningkatnya secara drastis penggunaan teknologi produksi sebagai contoh ekspansi jalur telegraf dan kereta api serta penggunaan elektrifikasi.

Pada tahun 1970-an dimulai revolusi industri ketiga, di era ini bisa dikatakan sebagai revolusi digital karena waktu dan ruang sudah tidak lagi berjarak, semua bisa dikendalikan dan disimulasikan dengan sistem komputer. Sistem produksi bisa lebih berlipat ganda bila dibandingkan dengan menggunakan tenaga manusia. Sedangkan tahapan revolusi industri 4.0 dimulai sejak awal tahun 2010-an dengan ditandai era digital lebih canggih yang melibatkan literasi data tingkat tinggi, 
persaingan industri terjadi di dunia maya berbasis data dan pekerjaan dilakukan dengan sistem robotisasi. Berikut tahapan revolusi industri seperti diperlihatkan pada Gambar 1.

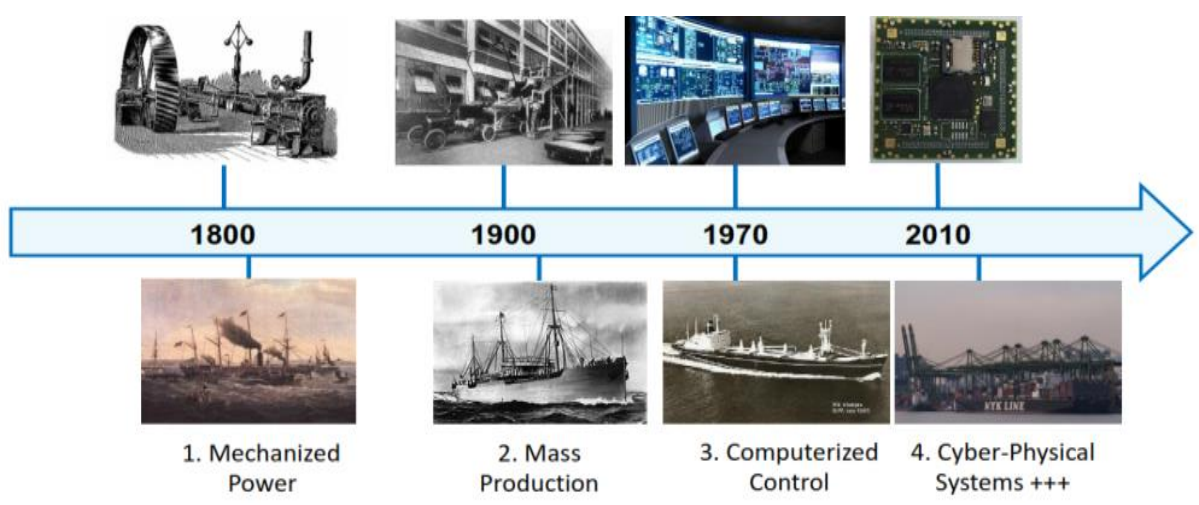

Gambar 1. Tahapan revolusi industri (Lervold,2017)

Tahapan revolusi industri keempat memberikan dampak yang sangat luas terhadap mata rantai industri kemaritiman yang harus menerapkan teknologi yang berbasis digital. Hal ini sejalan dengan pernyataan Carlan et.al (2018) bahwa ke depan akan semakin tumbuh transportasi maritim digital sebagai tulang punggung rantai penyuplai barang secara global, sehingga seluruh pemangku kepentingan harus mulai merubah dan mencari alternatif solusi dalam menjalankan upaya mencapai target masing-masing. Pelaku usaha industri kemaritiman seperti perusahaan pelayaran, pemilik kapal, dan tidak terkecuali perguruan tinggi kemaritiman segera mengevaluasi dan menyesuaikan dengan situasi dan tuntutan perkembangan di lapangan. Hal ini sejalan dengan pendapat Meade (dalam Lloyd's List,2017) yang mengemukakan revolusi industri 4.0 banyak menggunakan model digital dan canggih mengharuskan seluruh pihak yang terlibat atau stakeholders mengevaluasi apa yang telah diterapkan dan harus menyesuaikan dengan kebutuhan.

Digital disruption era memaksa pelaku usaha di industri kemaritiman untuk lebih selektif dalam hal menerima para lulusan dari perguruan tinggi kemaritiman yang siap bekerja dengan tantangan era baru, dimana segala usaha yang dihadapi melibatkan kecanggihan teknologi dan literasi data. Tuntutan industri kemaritiman ini menjadi tantangan bagi Perguruan Tinggi Kemaritiman di Indonesia dalam menyiapkan lulusannya, agar kompetensi lulusan mampu bersaing dan sesuai dengan kebutuhan dunia kerja baik dalam pengelolaan pelabuhan maupun sebagai perwira di atas kapal. Disamping itu lulusan juga dituntut untuk lebih inovatif dan adatif terhadap kemajuan teknologi berbasis digital.

Untuk menghasilkan lulusan berkualitas sesuai harapan, Perguruan Tinggi Kemaritiman harus melakukan berbagai analisis terkait dengan pengelolaan pendidikan, sehingga akan dapat menentukan strategi-strategi sesuai dengan capaian komptensi lulusan yang diharapkan. Pengelolaan pendidikan yang 
berorientasi global akan dapat menjawab berbagai kebutuhan di pasar kerja, melalui penyiapan sarana dan prasarana pembelajaran berbasis teknologi informasi, sumber daya manusia yang berkualitas, dan merekonstruksi kurikulum dengan pendekatan human digital. Hal ini sejalan dengan pendapat Muhammad Nasir (2018), Perguruan Tinggi sebagai penghasil SDM yang inovatif, adaptif terhadap teknologi sehingga dapat berkompetisi di dunia kerja harus melakukan beberapa hal, antara lain: melakukan penyesuaian sarana-prasarana fasilitas pembelajaran yang berbasis teknologi informasi, analisis big data dan komputerisasi, tenaga pendidik yang kompeten dengan menguasai teknologi digital dan merekonstruksi kurikulum dengan pendekatan human digital.

\section{METODE}

Metode yang digunakan dalam library research ini adalah dengan melakukan kajian terhadap jurnal-jurnal terkait perkembangan era digitalisasi menuju era revolusi industri 4.0 dan melacak semua jurnal terkait apa saja perubahan signifikan, tantangan beserta hambatan yang barangkali akan dihadapi sehingga bisa disimpulkan kesiapan dan strategi yang harus diambil atau dilakukan untuk menghadapi era dengan kemajuan teknologi yang super cepat tersebut. Analisis terhadap setiap konsep dan teori dari setiap jurnal ataupun pustaka yang ditelaah bersifat komparatif dan korelatif.

\section{HASIL DAN PEMBAHASAN}

\section{Konversi Kurikulum Berbasis Digital}

Dampak dari era revolusi industri 4.0 pada industri kemaritiman salah satunya adalah adanya transportasi otomatis bahkan tanpa awak dengan sistem data digital yang super canggih. Seperti contoh kapal Huster-68 berbendera China seperti dilansir Kompas.com tanggal 05 Februari 2018 yang merupakan kapal tanpa awak dengan misi menjaga keamanan laut China. Oleh karena itu sangat jelas bahwa yang perlu dipersiapkan saat ini adalah sumber daya manusia yang akan menggerakkan kapal dan terlibat dalam industri kemaritiman haruslah benar-benar kompeten dan mampu menguasai teknologi yang sudah berbasis literasi data tingkat tinggi. Hal ini juga dikuatkan oleh Taxgaard (dalam Lloyd's List,2017) yang menegaskan bahwa dalam dunia digital yang penting bukan bagaimana membuat internet atau pelayaran cerdas, tetapi bagaimana menciptakan manusia cerdas dibidangnya untuk menjalankan tugas dan mencapai sasaran.

Lervold (2017) mengatakan bahwa era digitalisasi pada revolusi industri 4.0 di dunia kemaritiman melibatkan 9 langkah besar yang menjadi fokus utama perubahan atau perkembangan. Di antara 9 fokus perkembangan tersebut adalah penggunaan cyber-physical system sistem berbasis software terintegrasi cerdas yang antara lain mampu mengkoneksikan dan mengkontrol pekerjaan di ruang yang berbeda. Jarak dan waktu menjadi sangat dekat dan bukan menjadi kendala. Robotics and autonomy penggunaan robot atau mesin otomatis sebagai pengganti tenaga manusia dalam menjalankan suatu misi atau tugas. Cyber security penggunaan teknologi komputer canggih untuk mengendalikan keamanan data, pengamanan sistem computer dari adanya disrupsi. 
Internet of things at sea penggunaan internet sebagai pendukung konektivitas di atas kapal atau di laut antara kapal dengan stasiun pantai dengan satelit. Selain itu internet sebagai media atau sistem navigasi elektronik. Augmented reality penggunaan sistem identifikasi elektronik lebih canggih dibandingkan ECDIS di atas kapal. Selain itu juga memberikan gambaran lebih jelas akan suatu titik focus. Data analytics, perkembangan teknologi analisis data misalnya teknologi analisa kecepatan maupun performa kapal, analisa data yang diberikan oleh alat navigasi elektronik di atas kapal seperti AIS, analisa volume kapal dan lainnya.

Simulation and optimization yaitu penggunaan simulator sebagai miniatur alat yang bisa memberikan gambaran nyata akan suatu pekerjaan yang dihasilkan, misalnya penggunaan simulator kapal. Internet services at sea yakni penggunaan internet sebagai prosedur kerja misalnya prosedur perencanaan perawatan dan monitoring kapal, prosedur pembuatan rute pelayaran, prosedur administrasi, dan lainnya. Open system integration penggunaan sistem teknologi terintegrasi di atas kapal untuk menjaga interkoneksi sistem yang ada.

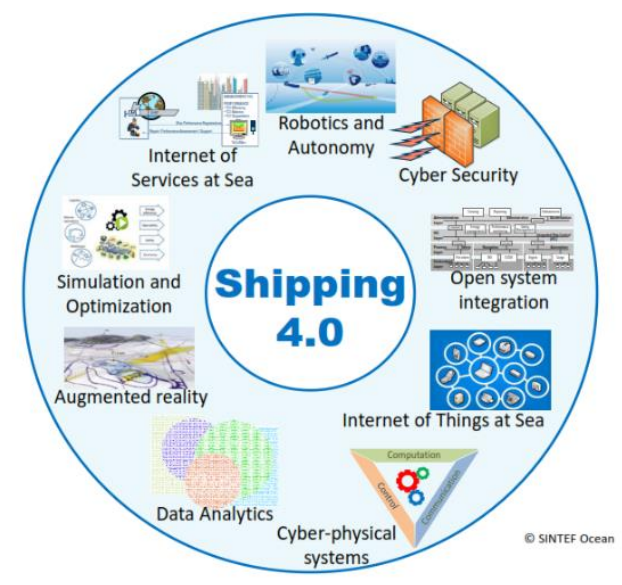

Gambar 2. Sembilan Fokus Utama Revolusi Industri 4.0 (Lervold,2017)

Dari Sembilan tahapan diatas sudah layaknya menjadi bahan pertimbangan untuk penyusunan kurikulum pada perguruan tinggi kemaritiman yang ada di Indonesia. Hal tersebut supaya output yang dihasilkan oleh perguruan tinggi kemaritiman Indonesia mempunyai outcome yang sesuai dengan permintaan atau kebutuhan di pasar kerja. Para lulusan harus dibekali dengan kemampuan dan ketrampilan teknologi yang tinggi yang melampaui kriteria minimal standar pelaut internasional. Oleh karena itu perlu diciptakan grand design perubahan kurikulum yang berbasis pendekatan human digital.

\section{Sarana Prasarana Pembelajaran dan Tenaga Pendidik}

Sarana dan prasarana pembelajaran harus tersedia secara memadai dan sesuai tujuan pendidikan yang telah ditetapkan, sehingga akan menghasilkan lulusan yang berkualitas sesuai kebutuhan dunia kerja. Salah satu contoh, laboratorium simulator yang wajib dimiliki bagi perguruan tinggi kemaritiman untuk pembelajaran calon perwira pelaut. Dengan laboratorium simulator tersebut diharapkan peserta didik belajar sesuai kenyataan yang terjadi di tempat kerja 
sebagai seorang pelaut. Belajar dengan menggunakan simulator peserta didik seolah-olah berada di atas kapal yang sesungguhnya sehingga mereka bisa mempunyai keterampilan dan pengetahuan yang kompeten. Selanjutnya untuk mendapatkan peserta didik yang mempunyai pengetahuan dan keterampilan yang sesuai sesuai tujuan kurikulum, tentunya pihak pengelola Perguruan Tinggi Kemaritiman harus menyediakan berbagai peralatan yang digunakan, sepertinya: laboratorium simulator, laboratorium Computer Based Training (CBT) dan lainnya.

Pemanfaatan sarana prasarana pembelajaran yang ada harus didukung dengan tenaga pendidik yang berkualitas yang bisa menyesuaikan dengan perkembangan teknologi. Tenaga pendidik harus mampu mentransfer ilmu yang perlu dikuasai peserta didik dengan melibatkan teknologi sesuai tuntutan kerja para peserta didik di masa depan. Untuk dapat melaksanakan proses pembelajaran seperti contoh diatas diperlukan tenaga pendidik yang memiliki keahlian berbasis digital dan memiliki sertifikat standar diantaranya TOT 6.09, TOE 3.12 dan TOT 6.10. Hal ini dibutuhkan ketersediaan sarana-prasana pembelajaran yang memadai berbasis teknologi informasi, analisis big data dan komputerisasi. Dengan demikian adanya kurikulum yang disusun sesuai jamannya di era revolusi industri 4.0 didukung dengan sarana prasarana pembelajaran terutama laboratorium yang memadai dan tenaga pendidik yang berkompeten serta mampu mengikuti perkembangan dan dinamika teknologi tingkat tinggi maka akan memberikan kontribusi terhadap kesiapan menghadapi era pelayaran cerdas smart shipping 4.0.

\section{SIMPULAN}

1. Tuntutan industri kemaritiman dalam Revolusi Industri 4.0 membutuhkan SDM yang memiliki kompetensi yang dapat merefleksikan kecanggihan teknologi dan literasi data yang berbasis pada kecepatan perkembangan teknologi sehingga akan lebih inovatif dan adatif pada lingkungan kerjanya.

2. Perguruan Tinggi Kemaritiman harus tanggap dalam menyikapi perubahan paradigma yang terjadi dengan merumuskan grand design perubahan kurikulum yang berbasis pendekatan human digital, melakukan penyesuaian sarana-prasarana pembelajaran yang berbasis teknologi informasi, analisis big data, komputerisasi serta tersedianya tenaga pendidik yang kompeten dan menguasai teknologi digital sehingga lulusannya sesuai dengan kebutuhan perkembangan industri kemaritiman dunia.

\section{DAFTAR PUSTAKA}

Carlan,Valentin.,Christa Sys.,Agustina Calatayud.,Thierry Vanelslander. (2018). Digital Innovation in Maritime supply Chain. IDB-DP-577. https://publications.iadb.org/handle/11319/8850. Diakses 1 Oktober 2018

Hribernik,Karl.(2016).Industry 4.0 In The Maritime Sector Potential and Challenges.BIBA. http://www.mlit.go.jp/common/001127983.pdf. Di akses 1 Oktober 2018 
Kobylinski,Lech. (2016). Marine Transport and The Fourth Industrial Revolution. https://webcache.googleusercontent.com/search?q=cache:XZ_T5uI5xjgJ:http s://www.wt.pw.edu.pl/content/download/6256/35235/file/Lech\%2520Kobyli \%25C5\%2584ski.pdf+\&cd=1\&hl=id\&ct=clnk\&gl=id.$d i a k s e s 5$ Oktober 2018

Lervold, Beate Kvamstad.(2017).9 Paths into The Maritime Future.SINTEF. http://haugesundkonferansen.no/content/uploads/2017/02/Beate-KvamstadLervold.pdf. Diakses 1 Oktober 2018

Lloyd's List.(2017).Digital Disruption-Managing the Transition to Smart Shipping.Lloyd's List Business Briefing.01-13. https://maritimeintelligence.informa.com/resources/key-topics/digitaldisruption. Diakses 15 Oktober 2018

Nasir, Muhammad (2018) Tantangan di Era Revolusi Industri 4.0 Bagi Perguruan Tinggi Indonesia, https://www.quipper.com/id/blog/quipper-campus/campusinfo/revolusi-industri-4-0/. Diakses (25 Oktober 2018)

Stanic, Venesa.Marco Hadjina,Niksa Fafandjel, Tin Matulja.(2018). Toward Shipbuilding 4.0-An industry 4.0 Changing the face of The Shipbuilding Industry. Brodogradnja /shipbuilding/open access. Vol.69 No.3. http://dx.doi.org/10.21278/brod69307. Diakses pada 17 Oktober 2018

https://www.lr.org/en/insights/global-marine-trends-2030/global-marinetechnology-trends-2030/. Global Marine Technology Trends 2030.2017.Diakses pada 4 Oktober 2018 